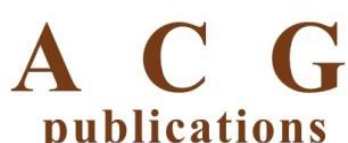

J. Chem. Metrol. 15:1 (2021) 76-87

journal of chemical metrology

\title{
Increasing the production of some specific cytotoxic triterpenoids and evaluation of the morpho-physiological response associated with in vitro salt stress in Pistacia khinjuk Stocks.
}

\author{
Emine Ayaz-Tilkat \\ Batman University, Faculty of Science and Literature, Department of Biology, \\ Batı Raman Campus, 72100, Batman, Türkiye
}

(Received October 30, 2020; Revised December 12, 2020; Accepted December 13, 2020)

\begin{abstract}
Triterpenoids are a class of secondary metabolites that are known to exhibit and possess various biological activities. Using plant biotechnological tools, a novel approach for producing these compounds offers opportunities not only to produce such bioactive secondary metabolites but also to increase the quantities of these essential phytochemicals. Therefore, this study was aimed to elucidate the biosynthesis of some cytotoxic triterpenoids through in vitro micropropagation of Pistacia khinjuk Stocks with the application of different $\mathrm{NaCl}$ concentrations ( 0 to $250 \mathrm{mM}$ ) and to evaluate the triterpenoids content as well as synchronize the morpho-physiological properties of plant materials during the salt application. The effects of these salt concentrations were investigated on $P$. khinjuk seedlings grown for four weeks by using the MS medium supplemented with $100 \mathrm{mg} / \mathrm{L} \mathrm{L}$-ascorbic acid and $\mathrm{NaCl}$ of given concentrations. LC-MS/MS results showed that the amount of all triterpenoid types from different plant parts was increased while root-shoot lengths, RWC, total $\mathrm{Chl}, \mathrm{Chl}-\mathrm{a} / \mathrm{b}$, and carotenoid values were decreased significantly at high salinity concentrations $(150 \mathrm{mM})$. The reduction of the quantitative and qualitative morphophysiological parameters was due to the production of an increased amount of secondary compounds, i.e., triterpenoids rather than primary compounds in response to the increased salt concentrations.
\end{abstract}

Keywords: Pistacia khinjuk Stocks; LC-MS/MS; salt stress; triterpenoid; in vitro; plant physiology. @ 2021 ACG Publications. All rights reserved.

\section{Introduction}

Many higher plants accumulate a variety of secondary metabolites which play the vital roles in many essential defense mechanisms such as defenses against salinity, drought, and ultraviolet radiation stress along with microorganisms and herbivores and allelopathy [1]. Plant secondary metabolites are highly variable in their chemical construction. Plant-derived secondary metabolites display far-going therapeutic and pharmaceutical properties [2]. Among all the plant secondary metabolites, terpenoids (mono, -di, tri etc.) represent the most diverse and major category of metabolites widely distributed in almost all plant groups [3,4]. Many medicinal activities like antimicrobial, antifungal, antiparasitic, antiviral potentials of these triterpenoids have been discovered by numerous studies [5, 6]. Moreover, they have also been utilized for preventing cancer and other several diseases due to their antiinflammatory, antihyperglycemic, antispasmodic, anti-allergenic, and immunomodulatory properties [7]. Secondary phytochemicals can be obtained naturally by conventional agricultural methods which

\footnotetext{
* Corresponding author e-mail: eayaztilkat@gmail.com
} 
eventually depend on season, climate and geographical location as well as the growth conditions of plants. Therefore, production of secondary metabolites through in vitro micropropagation could be a fruitful approach since approximately 50,000 defined secondary metabolites, and more than 30,000 bioactive chemical compounds have been produced through plant tissue cultures [8]. The capacity of producing secondary metabolites was found to be higher in differentiated tissues such as root, embryo, and shoot cultures compared to undifferentiated callus and cell suspensions [9-11]. Besides, it was observed that micropropagated plant parts might produce a higher amount of substances than the plants in nature [12]. Furthermore, biotechnological methods with the use of elicitors or precursor compounds such as biotic and abiotic stress sources can influence the higher accumulation of secondary metabolite [13]. However, type of stress or elicitors, the genotype and developing stage of a plant, structure of the tissue or organ, and the duration of exposure to the stress play crucial roles in tolerance of plants to stress factors. Many studies have been reported on the production of secondary metabolites by in vitro propagation of plants under abiotic stress conditions [14-17].

Nowadays, a significant amount of agronomy area in the world is affected by salinity [18]. Salt stress is one of the potential abiotic stresses, occurs naturally in coastal salt marshes (especially estuaries) and desert areas as well as in long-term and highly irrigated agricultural areas, particularly in arid regions [18]. Salinity can be defined as the accumulation of excessive salt by plants in term of inorganic ions, including $\mathrm{Mg}^{2+}, \mathrm{Na}^{+}, \mathrm{Ca}^{2+}, \mathrm{K}^{+}, \mathrm{SO}^{2-}, \mathrm{HCO}_{3}{ }^{-}$and $\mathrm{Cl}^{-}[19,20]$. It exhibits significant negative impacts on almost all physiological phenomena, biochemical processes, and morphological traits, i.e., ion toxicity and a decrease in photosynthesis activity, increase in respiration rate, disruption in mineral conveyance, disruption of nitrate and carbon metabolisms, ionic imbalance in the cell membrane, and finally reduction of plant growth [21,22]. In vitro micropropagation of the plant with the salt-containing condition may cause secondary metabolite production as well as morphological changes [23]. However, there are limited studies on the secondary metabolite production of Pistacia species through in vitro tissue culture methods [6].

The khinjuk pistachio (Pistacia khinjuk Stocks) possesses strong acrid resinous smell and belongs to the family Anacardiaceae. They can grow naturally under severe arid and semi-arid conditions in the

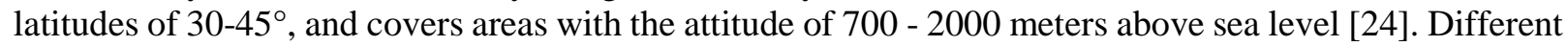
plant parts (resin, fruit, and leaves) of Pistacia species are used to treat several diseases for a long time due to their antimicrobial, anti-inflammatory, antiatherogenic, wound healing, blood pressure-lowering, and anticancer properties [25-28]. The effect of salinity on the quantity and quality of minerals and soluble sugars, proline accumulation, stomatal frequency and other morphological changes in leaves of different Pistacia species were reported; however, minimal information was found regarding the physiological response of khinjuk pistachio (Pistacia khinjuk Stocks) to saline stress [29-33].

Various in vitro propagation approaches have been reported in recent time to estimate the effects of salt stress on Pistacia and other species [34-36]. There is no study in the literature about the production of triterpenoids associated with the propagation of Pistacia khinjuk Stocks in in vitro salinity condition. In this context, this study aimed to investigate the effects of salt stress on in vitro shoot cultures of $P$. khinjuk Stocks considering some morpho-physiological responses on the germination. Besides, the production of some anticancer potential containing triterpenoids was also measured in this salt stress condition.

\section{Experimental}

\subsection{Materials and Methods}

\subsubsection{Salt Treatments}

For this study, salt solutions of 5 different concentrations $(50,100,150,200$, and $250 \mathrm{mM})$ were prepared. These salt solutions were added into the MS medium [37] to investigate the responses of micropropagated plantlets regarding both triterpenoid content and morpho-physiological properties. 


\subsubsection{Obtaining Shoot Cultures and Elicitation Treatments}

The seeds of Pistacia khinjuk Stocks were supplied by Gaziantep Pistachio Research Institute. The protocol developed by Tilkat et al. [38] was used for surface sterilization of seeds, culture initiation, and obtaining the stock cultures. The seeds were surface sterilized by immersing in a $20 \%(\mathrm{w} / \mathrm{v})$ commercial bleach solution $(\mathrm{NaOCl})$ for $30 \mathrm{~min}$. Afterwards, the seed coats were removed, and the kernels were washed three times with sterile distilled water before inoculating onto the MS basal medium. MS basal medium supplemented with $100 \mathrm{mg} / \mathrm{L}$, L-ascorbic acid, $3 \%$ sucrose (w/v), and solidified with $\operatorname{agar}\left(0.7 \%\right.$, w/v) was adjusted to $\mathrm{pH} 5.7$ before autoclaving $\left(120^{\circ} \mathrm{C}\right.$ for $\left.20 \mathrm{~min}\right)$. Cultures were maintained at $25 \pm 2^{\circ} \mathrm{C}$ with a $16 \mathrm{~h}$ photoperiod $\left(40 \mu \mathrm{mol} \mathrm{m}^{-2} \mathrm{~s}^{-1}\right)$ cycle. Approximately $1 \mathrm{~cm}$ long shoots from in vitro axenic stock medium of $P$. khinjuk Stocks were taken and cultured in MS medium containing different salt concentrations $(0,50,100,150,200,250 \mathrm{mM})$ along with a control group in a culture period of 28 days. After the end of this culture period, root, shoot, and leave of plantlets were dried separately and stored at $4^{\circ} \mathrm{C}$ for triterpenoid analysis.

\subsection{Observation of Morphological Changes}

After 28 days of seedling, three randomly selected plantlets from each treatment were selected for measuring the length of root and shoot. Symptoms developed in leaves were also observed in terms of morphological changes. Visible leaf damage was determined using a scale of 1-6 modified from Mohanty and Ong [39] as below:

$1=0 \%$ no yellow leaves; $2=10-30 \%$ yellow leaves; $3=30-50 \%$ yellow leaves; $4=50-70 \%$ yellow leaves, $5=$ most leaves were yellow; and $6=$ all leaves were yellow.

\subsection{Determination of Relative Water Content (RWC)}

Relative water content (RWC) was determined according to previously described method in the literature [40]. Fresh $0.5 \mathrm{~g}$ of each leaf samples were placed in distilled water for $4 \mathrm{~h}$. Then, the turgid weight of the disc of samples was measured. The dry weight of samples was also measured after drying the samples in an oven for $48 \mathrm{~h}$ at $65^{\circ} \mathrm{C}$, and the following formula was used for calculating RWC of each sample:

$$
\mathrm{RWC}=[(\text { fresh weight }- \text { dry weight }) /(\text { turgid weight }- \text { dry weight })] \times 100 .
$$

\subsection{Determination of Chlorophyll and Carotenoid Content}

The primary pigment content was calculated based on the study of Arnon [41]. $100 \mathrm{mg}$ of the fresh leaf was extracted by grinding in a mortar by using $15 \mathrm{ml}$ of $80 \%$ acetone. The extract was filtered through white stripe filter paper; the absorbance values of these filtered extracts were measured against the distilled water for total chlorophyll content at $652 \mathrm{~nm}$, for chlorophyll-a at $663 \mathrm{~nm}$, for chlorophyll-b at $646 \mathrm{~nm}$ and carotenoid at $470 \mathrm{~nm}$. Three replicates were used for each treatment, and the amount of pigment present in each sample was calculated according to the following equations [42] (A: Absorbance value reading):

Total chlorophyll $=(\mathrm{A} 652 \times 27.8) / \mathrm{mg}$ specimen weight

Chlorophyll a $(\mu \mathrm{g} / \mathrm{mL})=(12.21 \times A 663-2.81 \times A 646) / \mathrm{mg}$ specimen weight

Chlorophyll b $(\mu \mathrm{g} / \mathrm{mL})=(20.13 \times A 646-5.03 \times A 663) / \mathrm{mg}$ specimen weight

Carotenoid $(\mu \mathrm{g} / \mathrm{mL})=(1000 \times A 470-3.27[\mathrm{Cl}-\mathrm{a}]-104[\mathrm{Cl}-\mathrm{b}] / 227) / \mathrm{mg}$ specimen weight

\subsection{Triterpenoid Measurements by LC-MS/MS}


Dried extracts from shoot cultures were analyzed by Shimadzu brand ultra-high-performance liquid chromatography (UHPLC). Dried plant materials were diluted with methanol (500 mg/kg), which was injected into the LC-MS/MS through a $0.22 \mu \mathrm{m}$ filter.

\subsection{LC-MS/MS Method Development and Validation}

Quantitative analysis of the 6 triterpenoids used in this study was performed using the method developed within the TUBITAK project previously completed by Tilkat et al. [6]. According to the method, quantitative investigation of 6 triterpenoids in the studied samples was performed by using highperformance liquid chromatography-tandem mass spectrometry technique (LC-MS/MS). The system used was a Shimadzu brand LC-MS-8040 instrument. The column parameters were; $100 \mathrm{~mm} \times 2,1 \mathrm{~mm}, 2 \mu \mathrm{m}$, The column temperature; $30{ }^{\circ} \mathrm{C}$, Mobile phases; A: water, $10 \mathrm{mM}$ ammonium formate and $\mathrm{B}$ : methanol, $10 \mathrm{mM}$ ammonium formate. The gradient program; 85\% B (35 min).

In this study, an LC-MS/MS method was optimized and validated for the quantification of 6 triterpenoids in the studied samples. The performance characteristics of the method were determined by using standard solutions, spiked and non-spiked samples. Within this context, the developed method was fully validated in terms of linearity, accuracy (recovery), inter-day and intra-day precision (repeatability), limits of detection and quantification (LOD/LOQ) and relative standard uncertainty (U\% at $95 \%$ confidence level $(\mathrm{k}=2)$ ). Parameters related to the LC-MS/MS method validation studies are given in Table 1 .

\subsubsection{Linearity}

The linearity was assayed using external standard calibration curve with six concentration levels for each analyte, and each concentration level was assayed in triplicate. The developed method showed to be linear for all compounds, between the ranges of tested concentrations during the validation of the method with $R^{2} \geq 0.989$. The equations for the calibration curves and the determination coefficients $\left(R^{2}\right)$ are shown in Table 1 .

\subsubsection{Accuracy (Recovery) and Precision (Repeatability)}

Accuracy and precision studies of the method were performed by standard addition to a selected extract. For intra-day variability assessment, spiked samples were measured for six replicates within a single day, whereas spiked samples were examined in triplicate per day for three consecutive days to conduct inter-day assay. As a result of the studies conducted on the same day and on different days, recovery and \% RSD values were calculated to determine the accuracy and precision (Table 1). The recovery was calculated with the following equation: recovery $(\%)=($ amount found - original amount)/amount spiked $\times 100 \%$.

\subsubsection{Limits of Detection and Quantification (LOD/LOQ)}

To determine the LOD and LOQ values for the phytochemicals used in the LC-MS/MS method, analyte mixture were spiked at 10 identical samples prepared from a selected extract at the lowest concentration signaled by the standards and injected to the instrument. LOD and LOQ values were calculated according to the following equations (Table 1):

LOD $=$ Mean $+3 \times$ Standard Deviation

$\mathrm{LOQ}=$ Mean $+10 \times$ Standard Deviation

\subsubsection{Relative Standard Uncertainty $\left(U^{95}\right)$}

Standard uncertainties of the analytes were determined by the accuracy (recovery) and precision (repeatability) studies according to EURACHEM Guide [43] 
Table 1. Analytical parameters that belong to the LC-MS/MS method

\begin{tabular}{|c|c|c|c|c|c|c|c|c|c|c|c|c|c|c|}
\hline \multirow{2}{*}{ No } & \multirow{2}{*}{ Analytes } & \multirow[b]{2}{*}{$\mathbf{R T}^{\mathbf{a}}$} & \multirow{2}{*}{$\begin{array}{c}\text { Parent } \\
\text { ion } \\
(m / z)^{\mathrm{b}}\end{array}$} & \multirow{2}{*}{$\begin{array}{c}\text { Daughter } \\
\text { ion } \\
(m / z)^{b}\end{array}$} & \multirow{2}{*}{$\begin{array}{l}\text { Ion. } \\
\text { mode }\end{array}$} & \multirow{2}{*}{ Equation } & \multirow[b]{2}{*}{$\mathbf{R}^{2 \mathrm{c}}$} & \multicolumn{2}{|c|}{ RSD\% ${ }^{d}$} & \multirow{2}{*}{$\begin{array}{l}\text { Linearity } \\
\text { Range } \\
(\mathbf{m g} / \mathbf{L})\end{array}$} & \multirow{2}{*}{$\begin{array}{c}\mathrm{LOD} / \mathrm{LOQ} \\
(\mu \mathrm{g} / \mathrm{L})^{\mathrm{e}}\end{array}$} & \multicolumn{2}{|c|}{$\begin{array}{c}\text { Recovery } \\
(\%)\end{array}$} & \multirow[t]{2}{*}{$\mathbf{U}^{\mathrm{f}}$} \\
\hline & & & & & & & & $\begin{array}{l}\text { Inter } \\
\text { day }\end{array}$ & $\begin{array}{c}\text { Intra } \\
\text { day }\end{array}$ & & & $\begin{array}{c}\text { Inter } \\
\text { day }\end{array}$ & $\begin{array}{l}\text { Intra } \\
\text { day }\end{array}$ & \\
\hline 1 & Ursolic acid & 18.9 & 457.4 & 411.1 & Pos. & $y=90374.5 x-3952.85$ & 0.998 & 0.004 & 0.007 & $0.25-4.5$ & $0.131 / 0.147$ & 100.5 & 99.9 & 0.013 \\
\hline 2 & Ursonic acid & 19.5 & 453.2 & 453.3 & Neg. & $y=459342 \times-988.44$ & 0.990 & 0.005 & 0.005 & $0.25-4.5$ & $0.108 / 0.119$ & 104.4 & 102.4 & 0.059 \\
\hline 3 & Moronic acid & 23.5 & 453.2 & 453.3 & Neg. & $y=49695.9 x-19247.8$ & 0.997 & 2.699 & 0.009 & $1-18$ & $0.420 / 0.455$ & 102.2 & 101.8 & 0.020 \\
\hline 4 & Oleanonic acid & 22.9 & 453.2 & 453.3 & Neg. & $y=541816 x-566373$ & 0.990 & 5.391 & 0.001 & $1-18$ & $0.583 / 1.712$ & 106.5 & 101.6 & 0.009 \\
\hline 5 & Oleanolic acid & 1.0 & 208.9 & 59.1 & Neg. & $y=94087.1 \times-12986.1$ & 0.999 & 2.711 & 0.007 & $1-18$ & $0.108 / 0.122$ & 102.0 & 101.7 & 0.015 \\
\hline 6 & Masticadienolic acid & 25.47 & 455.3 & 453.3 & Neg. & $y=628603 \times-57141.4$ & 0.999 & 0.018 & 0.005 & $0.5-9$ & $0.213 / 0.231$ & 100.8 & 101.1 & 0.010 \\
\hline
\end{tabular}

${ }^{\mathrm{a}} \mathrm{RT}$ : Retention time, ${ }^{\mathrm{b}}$ Mother ion $(\mathrm{m} / \mathrm{z})$ : Molecular ions of the standard compounds $\left(\mathrm{m} / \mathrm{z}\right.$ ratio), ${ }^{\mathrm{C}}{ }^{2}$ : Coefficient of determination, ${ }^{\mathrm{d}} \mathrm{RSD}$ : Relative standard deviation, ${ }^{\mathrm{e}} \mathrm{LOD} / \mathrm{LOQ}(\mu \mathrm{g} / \mathrm{L})$ : Limit of detection/quantification, ${ }^{\mathrm{f}} \mathrm{U}(\%)$ : percent relative uncertainty at 95\% confidence level $(\mathrm{k}=2)$. Pos.: Positive, Neg.: Negative 


\subsection{Statistical Analysis}

Using different parameters, measurements of all the plantlets were recorded after completing 28 days culture period of the salt treatment, and an average of 3-5 replicates were taken for per treatment. The significance was determined by the analysis of variance (ANOVA), and Duncan's new multiple range tests were used to calculate the differences among the treatment means. Data presented in percentages were subjected to chi-square $(\chi 2)$ analysis.

\section{Results and Discussion}

In this study, micropropagation protocol developed by Tilkat et al. [38] was applied to initiate the shoot culture from P. khinjuk Stocks seeds, and successful results were obtained from this method. After applying different concentrations of salt $(\mathrm{NaCl} ; 0,50,100,150,200,250 \mathrm{mM})$ in shoot cultures, the triterpenoid content, and the morphological and physiological properties of plants were measured, which are given below.

\subsubsection{Morphological Observations}

Morphological changes (root and shoot length and visible leaf damages) were evaluated after a culture period ( 28 days) of the $\mathrm{NaCl}$ treatment. According to Table 1 and Figure 1, the growth of the seedlings was decreased with the increase of salt concentration. Thick, large-sized, dark green-colored leaves were observed at control condition, which turned into light green color, especially at 50 and 100 $\mathrm{mM} \mathrm{NaCl}$ concentrations, and most of the leaves turned smaller and yellow color at $200-250 \mathrm{mM} \mathrm{NaCl}$ concentrations. Chlorosis is one of the most common symptoms of stress due to the decrease of chloroplastic pigments. In this study, this process (chlorosis) increased gradually with the increase of salt concentration. Visible leaf damage was also increased with the increase of salt concentration level. Furthermore, salinity also reduced root, shoot, and leaf lengths and relative water content values compared to the control.

\subsubsection{Physiological Observations}

The physiological changes in terms of the RWC values and the pigment contents are given in Table 2, and Table 3, respectively. With the increase in salinity ( 0 to $250 \mathrm{mM}$ ), salinity stress in this study gradually harms most of the physiological characteristics (Table 2). Pigment content is considered as one of the remarkable stress symptoms in salt-treated tissues. Compared with the control, the maximum inhibiting effect was recorded at high salt concentrations $(100-250 \mathrm{mM})$ for a culture period of 28 days. The relative total chlorophyll ( $\mathrm{Cl}-\mathrm{a}$, the $\mathrm{Cl}-\mathrm{b})$, and the carotenoid contents of in vitro P. khinjuk Stocks shoots with different salt stress concentrations are presented in Table 3.

Table 2. The effect of increased $\mathrm{NaCl}$ concentrations on the root-shoot lengths, the visible leaf damage and the RWC of the P. khinjuk Stocks seedlings"

\begin{tabular}{ccccc}
\hline Salt con. $(\mathbf{m M})$ & $\begin{array}{c}\text { Root lengths } \\
(\mathbf{c m})\end{array}$ & $\begin{array}{c}\text { Shoot lengths } \\
(\mathbf{c m})\end{array}$ & $\begin{array}{c}\text { Visible leaf } \\
\text { damage }\end{array}$ & RWC \\
\hline $\mathbf{0}$ & $18.80 \pm 1.14^{\mathrm{a}}$ & $4.50 \pm 0.29^{\mathrm{a}}$ & $1.00 \pm 0.00^{\mathrm{a}}$ & $53.11 \pm 0.13^{\mathrm{a}}$ \\
$\mathbf{5 0}$ & $18.75 \pm 1.80^{\mathrm{a}}$ & $3.00 \pm 0.14^{\mathrm{b}}$ & $1.20 \pm 0.10^{\mathrm{b}}$ & $50.0 \pm 1.08^{\mathrm{b}}$ \\
$\mathbf{1 0 0}$ & $14.45 \pm 0.62^{\mathrm{b}}$ & $2.50 \pm 0.16^{\mathrm{c}}$ & $2.40 \pm 0.11^{\mathrm{c}}$ & $45.89 \pm 0.05^{\mathrm{c}}$ \\
$\mathbf{1 5 0}$ & $5.40 \pm 0.55^{\mathrm{c}}$ & $2.30 \pm 0.11^{\mathrm{c}}$ & $3.20 \pm 0.64^{\mathrm{d}}$ & $41.48 \pm 0.07^{\mathrm{d}}$ \\
$\mathbf{2 0 0}$ & $4.45 \pm 0.43^{\mathrm{c}}$ & $1.80 \pm 0.06^{\mathrm{d}}$ & $4.30 \pm 0.65^{\mathrm{e}}$ & $38.84 \pm 0.09^{\mathrm{e}}$ \\
$\mathbf{2 5 0}$ & $1.19 \pm 0.11^{\mathrm{d}}$ & $1.15 \pm 0.07^{\mathrm{e}}$ & $5.30 \pm 5.59^{\mathrm{f}}$ & $34.9 \pm 0.09^{\mathrm{f}}$ \\
\hline
\end{tabular}

* Data represents an average of 3 replicates per treatment after 28 days of culture. Means in a row followed by the same lowercase letters are not significantly different at $\mathrm{P} \leq 0.05$ levels of significance according to Duncan's multiple range tests. 
The control group showed the highest amounts of total chlorophyll (36.47), chlorophyll-a (25.27), chlorophyll-b (11.20) and carotenoid (5.72) among all groups. The lowest chlorophyll content was measured at $250 \mathrm{mM}$ concentration. Total chlorophyll, chlorophyll-a, chlorophyll-b, and carotenoid values were very close to each other or similar from 100 to $250 \mathrm{mM} \mathrm{NaCl}$ concentration levels (Table 3).

Table 3. The effect of increased $\mathrm{NaCl}$ concentrations on the pigment contents of the $P$. khinjuk Stocks*

\begin{tabular}{ccccc}
\hline Salt con. $(\mathbf{m M})$ & Total Cl & Cl-a & Cl-b & Carotenoid \\
\hline $\mathbf{0}$ & $36.47 \pm 0.75^{\mathrm{a}}$ & $25.27 \pm 1.20^{\mathrm{a}}$ & $11.20 \pm 0.45^{\mathrm{a}}$ & $5.72 \pm 0.71^{\mathrm{a}}$ \\
$\mathbf{5 0}$ & $11.11 \pm 0.56^{\mathrm{b}}$ & $8.41 \pm 0.59^{\mathrm{b}}$ & $2.70 \pm 0.02^{\mathrm{b}}$ & $2.59 \pm 0.16^{\mathrm{b}}$ \\
$\mathbf{1 0 0}$ & $5.41 \pm 0.98^{\mathrm{c}}$ & $3.68 \pm 0.19^{\mathrm{c}}$ & $1.70 \pm 0.09^{\mathrm{c}}$ & $1.52 \pm 0.06^{\mathrm{c}}$ \\
$\mathbf{1 5 0}$ & $5.23 \pm 0.59^{\mathrm{c}}$ & $4.31 \pm 0.10^{\mathrm{c}}$ & $0.92 \pm 0.04^{\mathrm{d}}$ & $1.75 \pm 0.07^{\mathrm{c}}$ \\
$\mathbf{2 0 0}$ & $4.50 \pm 0.81^{\mathrm{d}}$ & $4.00 \pm 0.05^{\mathrm{c}}$ & $0.50 \pm 0.02^{\mathrm{e}}$ & $1.68 \pm 0.05^{\mathrm{c}}$ \\
$\mathbf{2 5 0}$ & $3.46 \pm 0.67^{\mathrm{e}}$ & $2.94 \pm 0.04^{\mathrm{d}}$ & $0.52 \pm 0.01^{\mathrm{e}}$ & $0.84 \pm 0.01^{\mathrm{d}}$ \\
\hline
\end{tabular}

* Data represents an average of 3 replicates per treatment after 28 days of culture.

Means in a row followed by the same lowercase letters are not significantly

different at $\mathrm{P} \leq 0.05$ levels of significance according to Duncan's multiple range tests.

\subsubsection{Terpenoid Content}

In the control group, the triterpenoids were absent in the roots and leaves; meanwhile, all triterpenoids (from Ursonic acid to Ursolic acid) were estimated in shoot extracts (Table 4). The triterpenoid synthesis was activated in leaves and roots at $50 \mathrm{mM}$ and $150 \mathrm{mM}$ salt levels, respectively. Besides, increased amount of all triterpenoid types was found in the root, shoot, and leaf at the salt elicitation of $150 \mathrm{mM}$ level; on the other hand, $200 \mathrm{mM}$ salt elicitation, however, was marked as the beginning of the adverse salt concentrations since it significantly reduced the triterpenoids contents in shoots and leaves. Moreover, the amount of triterpenoid in almost all parts was decreased at $250 \mathrm{mM}$ level (Table 4).

Table 4. The effect of $\mathrm{NaCl}$ elicitation on the triterpenoid content of the P. khinjuk Stocks root, shoot and leaves*

\begin{tabular}{|c|c|c|c|c|c|c|c|}
\hline $\begin{array}{c}\text { Explant } \\
\text { Type }\end{array}$ & $\begin{array}{l}\text { Salt con. } \\
(\mathrm{mM})\end{array}$ & $\begin{array}{c}\text { Ursonic } \\
\text { Acid }(\mu \mathrm{g} / \mathrm{g})\end{array}$ & $\begin{array}{c}\text { Moronic } \\
\text { Acid }(\mu \mathrm{g} / \mathrm{g})\end{array}$ & $\begin{array}{c}\text { Oleanonic } \\
\text { Acid }(\mu \mathrm{g} / \mathrm{g})\end{array}$ & $\begin{array}{c}\text { Masticadienolic } \\
\text { Acid }(\mu \mathrm{g} / \mathrm{g})\end{array}$ & $\begin{array}{c}\text { Oleanolic } \\
\text { Acid }(\mu \mathrm{g} / \mathrm{g})\end{array}$ & $\begin{array}{c}\text { Ursolic } \\
\text { Acid }(\mu \mathrm{g} / \mathrm{g})\end{array}$ \\
\hline \multirow{6}{*}{ Root } & Control & N.D. & N.D. & N.D. & N.D. & N.D. & N.D. \\
\hline & $50 \mathrm{mM}$ & N.D. & N.D. & N.D. & N.D. & N.D. & N.D. \\
\hline & $100 \mathrm{mM}$ & N.D. & N.D. & N.D. & N.D. & N.D. & N.D. \\
\hline & $150 \mathrm{mM}$ & $0.668 \pm 0.04^{b}$ & $0.003 \pm 0.01^{\mathrm{b}}$ & $0.016 \pm 0.01^{\mathrm{b}}$ & $0.028 \pm 0.01^{b}$ & $0.023 \pm 0.01^{\mathrm{b}}$ & $0.028 \pm 0.01^{\mathrm{b}}$ \\
\hline & $200 \mathrm{mM}$ & $2.512 \pm 0.15^{\mathrm{a}}$ & $0.007 \pm 0.01^{\mathrm{a}}$ & $0.068 \pm 0.01^{\mathrm{a}}$ & $0.110 \pm 0.01^{\mathrm{a}}$ & $0.135 \pm 0.01^{\mathrm{a}}$ & $0.114 \pm 0.01^{\mathrm{a}}$ \\
\hline & $250 \mathrm{mM}$ & $0.439 \pm 0.03^{c}$ & $0.001 \pm 0.01^{\mathrm{c}}$ & $0.008 \pm 0.01^{\mathrm{c}}$ & $0.016 \pm 0.01^{\mathrm{c}}$ & $0.021 \pm 0.01^{\mathrm{c}}$ & $0.020 \pm 0.01^{\mathrm{c}}$ \\
\hline \multirow{6}{*}{ Shoot } & Control & $0.984 \pm 0.06^{\mathrm{a}}$ & $0.082 \pm 0.02^{\mathrm{a}}$ & $0.033 \pm 0.01^{\mathrm{b}}$ & $0.037 \pm 0.01^{\mathrm{b}}$ & $0.084 \pm 0.01^{\mathrm{a}}$ & $0.052 \pm 0.01^{\mathrm{b}}$ \\
\hline & $50 \mathrm{mM}$ & $0.807 \pm 0.05^{\mathrm{b}}$ & $0.024 \pm 0.01^{\mathrm{d}}$ & $0.023 \pm 0.01^{\mathrm{c}}$ & $0.031 \pm 0.01^{\mathrm{c}}$ & $0.030 \pm 0.01^{\mathrm{d}}$ & $0.051 \pm 0.01^{b}$ \\
\hline & $100 \mathrm{mM}$ & $1,067 \pm 0.06^{\mathrm{a}}$ & $0.016 \pm 0.01^{\mathrm{d}}$ & $0.015 \pm 0.01^{\mathrm{e}}$ & $0.043 \pm 0.01^{\mathrm{a}}$ & $0.024 \pm 0.01^{\mathrm{e}}$ & $0.024 \pm 0.01^{\mathrm{d}}$ \\
\hline & $150 \mathrm{mM}$ & $1.114 \pm 0.07^{\mathrm{a}}$ & $0.016 \pm 0.01^{\mathrm{d}}$ & $0.020 \pm 0.01^{\mathrm{d}}$ & $0.043 \pm 0.01^{\mathrm{a}}$ & $0.047 \pm 0.01^{\mathrm{b}}$ & $0.036 \pm 0.01^{\mathrm{c}}$ \\
\hline & $200 \mathrm{mM}$ & $1.103 \pm 0.07^{\mathrm{a}}$ & $0.002 \pm 0.01^{\mathrm{e}}$ & $0.003 \pm 0.01^{\mathrm{f}}$ & N.D. & $0.033 \pm 0.01^{\mathrm{c}}$ & $0.003 \pm 0.01^{\mathrm{e}}$ \\
\hline & $250 \mathrm{mM}$ & $1.063 \pm 0.06^{\mathrm{a}}$ & $0.021 \pm 0.01^{\mathrm{c}}$ & $0.095 \pm 0.01^{\mathrm{a}}$ & N.D & $0.017 \pm 0.01^{\mathrm{f}}$ & $0.094 \pm 0.01^{\mathrm{a}}$ \\
\hline \multirow{6}{*}{ Leaf } & Control & N.D. & N.D. & N.D. & N.D. & N.D. & N.D. \\
\hline & $50 \mathrm{mM}$ & $6.205 \pm 0.37^{\mathrm{a}}$ & $0.026 \pm 0.01^{\mathrm{b}}$ & $0.064 \pm 0.01^{\mathrm{b}}$ & $0.288 \pm 0.01^{\mathrm{a}}$ & $0.246 \pm 0.01^{\mathrm{b}}$ & $0.204 \pm 0.01^{\mathrm{a}}$ \\
\hline & $100 \mathrm{mM}$ & $0.442 \pm 0.03^{\mathrm{d}}$ & $0.013 \pm 0.01^{\mathrm{d}}$ & $0.018 \pm 0.01^{\mathrm{d}}$ & $0.020 \pm 0.01^{\mathrm{d}}$ & $0.051 \pm 0.01^{\mathrm{d}}$ & $0.011 \pm 0.01^{\mathrm{d}}$ \\
\hline & $150 \mathrm{mM}$ & $4.947 \pm 0.30^{\mathrm{b}}$ & $0.135 \pm 0.01^{\mathrm{a}}$ & $0.129 \pm 0.01^{\mathrm{a}}$ & $0.206 \pm 0.01^{b}$ & $0.388 \pm 0.01^{\mathrm{a}}$ & $0.153 \pm 0.01^{b}$ \\
\hline & $200 \mathrm{mM}$ & $0.783 \pm 0.05^{\mathrm{c}}$ & $0.024 \pm 0.01^{\mathrm{c}}$ & $0.046 \pm 0.01^{\mathrm{c}}$ & $0.031 \pm 0.01^{\mathrm{c}}$ & $0.067 \pm 0.01^{\mathrm{c}}$ & $0.032 \pm 0.01^{\mathrm{c}}$ \\
\hline & $250 \mathrm{mM}$ & $0.104 \pm 0.01^{\mathrm{e}}$ & $0.002 \pm 0.01^{\mathrm{e}}$ & $0.003 \pm 0.01^{\mathrm{e}}$ & $0.005 \pm 0.01^{\mathrm{e}}$ & $0.006 \pm 0.01^{\mathrm{e}}$ & $0.003 \pm 0.01^{\mathrm{e}}$ \\
\hline
\end{tabular}

* Analyzes performed on the LC-MS/MS are given as the results of 3 replicates. Results are given as $\mu \mathrm{g} / \mathrm{g}$ extract.

Each explant in a column has been evaluated among themselves. Means in a row followed by the same lowercase letters are not significantly different at $\mathrm{P} \leq 0.05$ levels of significance according to Duncan's multiple range tests, $* *$ N.D. $=$ Not Determined. 
In terms of salt concentrations applied at different levels, the ursonic acid was not observed in the leaves of the control group, while in the $50 \mathrm{mM}$ salt elicitation was synthesized at the rate of $6.205 \mathrm{ppm}$ and $150 \mathrm{mM}$ salt elicitation at a rate of $4.947 \mathrm{ppm}$. Again in terms of salt concentrations applied at different levels, ursonic acid was not observed in the leaves of the control group; however, it was found that at the level of $6.205 \mathrm{ppm}$ and $4.947 \mathrm{ppm}$ in $50 \mathrm{mM}$ and $150 \mathrm{mM}$ salt concentrations, respectively.

The production of secondary metabolites using biotechnological methods, including elicitor and precursor treatments, has many advantages over classical methods. To date, although there are many studies about the secondary metabolite content and cytotoxic activity in plants growing in nature $[44,45]$, several studies have shown that many commercial and medicinal plants can accumulate a higher amount of secondary metabolites through shoot cultures. For example, a high amount of bacoside from Bacopa monnieri; camptothecin from Nothapodytes nimmoniana; digitoxin from Digitalis purpurea L.; stevioside from Stevia rebaudiana; xanthone from Gentiana dinaricawere; anthraquinones from Oldenlandia umbellata L. rosmarinic acid from Ocimum basilicum L. were able to be synthesized from their shoot culture than naturally occurring plants [46, 47, 48, 49, 50, 51, 52]. Moreover, it is reported that the effect of elicitor applications for metabolite production depends on the conditions of the culture, applied timeperiod, and the concentration of the elicitor [12].

In this study, in vitro Pistacia khinjuk Stocks shoot culture with different levels of salt concentrations was used, and the amount and type of triterpenoids in leaves, shoots, and roots were investigated. Different levels of elicitation applied to $P$. khinjuk shoot culture produced several triterpenoids at different levels. For instance, $50 \mathrm{mM}$ and $25 \mathrm{mM} \mathrm{NaCl}$ elicitation in leaves increased the amount of ursonic acid 2.16 and 3.71 times compared to the control group, respectively. Moreover, the length of shoots and the synthesis of total chlorophyll, Chl-a, Chl-b, and carotenoid pigments decreased at $50 \mathrm{mM}$ salt level. Likewise, in vitro root culture of $P$. khinjuk Stocks with different salt concentrations showed that the amounts of various secondary metabolites were increased whereas root length started to decrease from $150 \mathrm{mM}$ salt level. All these outcomes indicated that at stress conditions, plants focus on the synthesis of secondary metabolites rather than primary metabolite production. It is well known that stress is one of the most critical environmental impacts that limits the growth and development of plants, changes the physiological and biochemical properties of plants, and increases the secondary metabolites contents, which play the crucial roles in the protection and defense systems of plants [23].

Although no studies on triterpenoid production from Pistacia species with salt stress have been found in the literature yet, there is a report on the application of $0.05 \mathrm{M}$ potassium chloride salt on Catharanthus roseus which indicated the increased production of ajmalicin four times compared to the control group [53]. In another study, Stevia rebaudiana plant was exposed to 6 different salt concentrations $(0,30,60$, 90,120 and $150 \mathrm{mM}$ ) for 62 days in which the highest amount of steviosid and rebaudiosid-A diterpenes was obtained from $30 \mathrm{mM}$ salt concentration [9].

For woody plants, the early developing stage, i.e., the seedling is usually the most salt-sensitive phase; hence, young seedlings could be a valuable material to detect initial salt responses [29]. Besides, visible alteration and damage in the leaf are other critical indicators for screening salt tolerance. Several studies indicated that leaf relative water content (RWC), total chlorophyll contents, and the carotenoid contents of leaves decreased during salt stress. It was observed that $\mathrm{NaCl}$ decreases the total chlorophyll content of both Pistacia atlantica Defs., and P. vera L. seedlings [32]. Furthermore, the decrease of chlorophyll content in leaves due to salt stress was observed from the effects of $\mathrm{SO}_{4}^{-2}, \mathrm{Cl}^{-}$and boron on pistachio rootstocks [54]; and the effects of $\mathrm{NaCl}$ and $\mathrm{CaCl}_{2}$ salt combinations on $P$. khinjuk Stocks and $P$. mutica L. [55]. The reduction of chlorophyll content may be the result of the adverse effects of salt on membrane stability [56]. Besides, it was reported that the total biomass of the shoots of P. vera $\mathrm{L}$. seedlings reduced on the 30th and 60th days due to salt stress [57]. Besides, in a study on P. vera $\mathrm{L}$. Badami-Zarand variety showed that the root-shoot length, the number of leaves, dry weight of shoots, and the rate of photosynthesis were decreased under salt stress [58].

The present study showed that increased $\mathrm{NaCl}$ concentrations increased terpenoid production at a certain level. Additionally, this given salt concentration exhibited adverse effects on the morphological and physiological properties of $P$. khinjuk Stocks, which disrupted the growth and development of plants. Production of valuable terpenoids using in vitro micropropagated $P$. khinjuk Stocks is very significant since this secondary metabolite group processes many biological functions, especially anticancer activity [28]. For instance, antiproliferative and apoptosis capacity of oleanolic acid in diverse tumor cells such 
as human pancreatic, colorectal, prostate, and bladder cells has been observed by several in vitro studies [59]. The cytotoxic effects of oleanolic acid and ursolic acid against the proliferation, growth and invasion of a variety of liver cancer cell lines were confirmed by several studies [60]. Oleanolic acid was found to have the potential to decrease the viability of different liver cancer cell lines i.e., HepG2, Hep3B, Huh7 and HA22T cells $[59,61]$. In a similar study, ursolic acid was found to have the inhibition capacity in the proliferation of R-HepG2 and HepG2 cell lines [62].

Furthermore, chios mastic gum and oil isolated from Pistacia lentiscus L. were identified to exhibit beneficial effects on a wide range of human disorders [63]. The inhibitory effects of mastic gum on the proliferation and cell cycle progression were observed in human prostate cancer PC-3 cells [64], promyelocytic leukemia HL-60 cells and myeloblastic leukemia ML-1 and KG-1 cells [65] etc. Triterpenoid analogues i.e., masticadienolic acid, oleanolic acid, oleanonic acid, ursolic acid, ursonic acid, dammaradienone, tirucallol, moronic acid etc. from mastic gum appeared to be mainly responsible for its anticancer potential [63].

Nevertheless, this study will be useful for elucidating the tolerance mechanisms of the Pistacia genus against salt stress, particularly for surviving high salt containing agricultural land in arid and in semi-arid climate conditions.

\section{Conclusions}

This study was conducted to investigate the effects of $\mathrm{NaCl}$ applications on growth and triterpenoid content of $P$. khinjuk Stocks. The result showed that the morpho-physiological properties of in vitro seedling were decreased as salt concentrations were increased. However, salt application synchronously increasing the amount and types of triterpenoids due to the induction of cellular defense mechanisms against salt stress. Therefore, the protocol established in this study could provide the guideline for carrying out detailed research on elicitation for producing a high amount of secondary metabolites from various plants, especially cytotoxic property containing triterpenoids for pharmaceutical benefits.

\section{Funding}

This work was supported by the [Batman University Research Project Council] under Grant [number BTUBAP-FEF001].

\section{Acknowledgements}

The author wishes to thank Dr. Israt JAHAN for her kind help in revising the manuscript from a linguistic point of view and Assoc. Prof. Dr . Abdullah YILMAZ and Assoc. Prof. Dr. Abdülselam Ertaş for helping in LC-MS/MS analysis and statistical analysis. The author wishes to thank Dr. Veysel Suzerer and Dr. Alevcan Kaplan for their supporting in biological activity and statistical analysis.

\section{Supporting Information}

Supporting information accompanies this paper on http://www.acgpubs.org/journal/ journalof-chemical-metrology

ORCID

Emine Ayaz-Tilkat: 0000-0001-5111-425X

\section{References}

[1] H.N. Murthy, E.J. Lee and K.Y. Paek (2014). Production of secondary metabolites from cell and organ cultures: strategies and approaches for biomass improvement, Plant Cell, Tiss. Organ Cult. 118, 1-6. 
[2] L. Satish, A.S. Rency, B.C. Muthubharathi, S. Shamili, R. Rameshkumar, M.K. Swamy and M. Ramesh (2019). Transgenic plant cell cultures: A promising approach for secondary metabolite production. Natural Bio-active Compounds, eds: Akhtar, M., Swamy, M., Springer, Singapore.

[3] D. Tholl (2015). Biosynthesis and biological functions of terpenoids in plants J. Schrader, J. Bohlmann (Eds.), Biotechnology of Isoprenoids, Adv. Biochem. Engin./Biotechnol. 148, 63-106.

[4] L.Q. Hung, P.T. Thuong and N.H. Tung (2019). A new Ursane-Type triterpene from the roots of Salvia miltiorrhiza bunge, Rec. Nat. Prod. 13, 429-433.

[5] G. Tsasi, P. Samara, O. Tsitsilonis, G. Jürgenliemk and H. Skaltsa (2016). Isolation, identification and cytotoxic activity of triterpenes and flavonoids from Green Walnut (Juglans regia L.) Pericarps, Rec. Nat. Prod. 10, 83-92.

[6] E. Tilkat, A. Ertaş, H. Surmuş-Aşan, M.A. Yılmaz and V. Süzerer (2018). The production of chemical components performing anticancer activity in in vitro culture of shoots, callus and suspension of Pistacia lentiscus L.] TÜBİTAK Project (114z842)Final Report 241p (In Turkish) https://app.trdizin.gov.tr/publication/project/detail/TVRjMk5UTXo=

[7] K.H. Wagner and I. Elmadfa (2003). Biological relevance of terpenoids. Overview focusing on mono-, diand tetraterpenes, Ann. Nutr. Metab. 47, 95-106.

[8] A. Güven and I. Gürsul (2014). Bitki doku kültürlerinde sekonder metabolit sentezi, Glda. 39, 299-306. (In Turkish)

[9] M.A. Shahverdi, H. Omidi and S.J. Tabatabaei (2017). Stevia (Stevia rebaudiana Bertoni) responses to $\mathrm{NaCl}$ stress: Growth, photosynthetic pigments, diterpene glycosides and ion content in root and shoot, $J$. Saudi Soc. Agric. Sci. 18, 355-360.

[10] M. Valifard, S. Mohsenzadeh, B. Kholdebarin and V. Rowshan (2014). Effects of salt stress on volatile compounds, total phenolic content and antioxidant activities of Salvia mirzayanii, S. Afr. J. Bot. 93, 92-97.

[11] S. Namlı, Ç. Isıkalan, F. Akbaş and E. Ayaz-Tilkat (2014). Effects of UV-B radiation on total phenolic, flavonoid and hypericin contents in Hypericum retusum Aucher grown under in vitro conditions, Nat. Prod. Res. 28, 2286-2292.

[12] M.T. Erkoyuncu ve M. Yorgancilar (2015). Bitki doku kültürü yöntemleri ile sekonder metabolitlerin üretimi. Selçuk Tarım Bil. Derg. 2, 66-76. (In Turkish)

[13] L. Ajungla, P.P. Patil, R.B. Barmukh and T.D. Nikam (2009). Influence of biotic and abiotic elicitors on accumulation of hiyosiyamin and scopolamine in root cultures of Datura metel L., Indian J. Biotechnol. 8, 317-322.

[14] P.M. Naik and J.M. Al-Khayri (2016). Abiotic and biotic elicitors role in secondary metabolites production through in vitro culture of medicinal plants, abiotic and botic stress in plants - Recent advances and future perspectives.doi: $10.5772 / 61442$.

[15] I. Kumar and S.R. Kumar (2018). Production of secondary metabolites in plants under abiotic stress: an overview, Signific. Bioeng. and Biosci. 2, 196-200.

[16] A. Zehra, S. Choudhary, M. Naeem, M.M.A Khan and T. Aftab (2019). A review of medicinal and aromatic plants and their secondary metabolites status under abiotic stress, J. Med. Plants Stud. 7, 99-106.

[17] S. Sharma, S. Sharma, S. Kukreja, V.S. Jadon and V. Sharma (2020). Plant tissue culture methods in secondary metabolite production-A mini review, Plant Cell Biotechnol. Mol. Biol. 21, 144-153.

[18] Z. Gengmao, H. Yu, S. Xing, L. Shihui, S. Quanmei and W. Changhai (2015). Salinity stress increases secondary metabolites and enzyme activity in safflower, Ind. Crops Prod. 64, 175-181.

[19] S. Yadav, M. Irfan, A. Ahmad and S. Hayat (2011). Causes of salinity and plant manifestations to salt stress: a review, J. Environ. Biol., 32, 667-85.

[20] D.M. Musyimi (2015). Ecology and physiology of plant growth in relation to soil salinity. Sci. Agric. Bohem., 11:26-31.

[21] M. Yıldı, H. Terzi, S.E. Cenkci, E.S. Arıkan-Terzi and B. Urusak (2010). Physiological and biochemical markers of salinity tolerance in plants, Anadolu Univ. J. Sci. Tec. A, 1, 1-33.

[22] H. Abbasi, M. Jamil, A. Haq, S. Ali, R. Ahmad and Z. Malik (2016). Salt stress manifestation on plants, mechanism of salt tolerance and potassium role in alleviating it: a review, Zemdirbyste 103, 229-238.

[23] M. Valifard, S. Mohsenzadeh, B. Kholdebarin, V. Rowshan, A. Niazi and A. Moghadam (2018). Effect of salt stress on terpenoid biosynthesis in Salvia mirzayanii: from gene to metabolite, J. Hortic. Sci. Biotechnol. 94, 1-11.

[24] A.G. Pirbalouti and K. Aghaee (2011). Chemical composition of essential oil of Pistacia khinjuk stocks grown in Bakhtiari Zagross Mountains, Iran J. Sci. Technol. Trans. A Sci. 7, 67-69.

[25] P. Marone, L. Bono, E. Leone, S. Bona, E. Carretto and L. Perversi (2001). Bactericidal activity of Pistacia lentiscus mastic gum against helicobacter pylor, Chemotheraphy 13, 611-614. 
[26] O.F. Akdemir, E. Tilkat, A. Onay, C. Keskin, M. Bashan, F.M. Kilinç, V. Kizmaz and Süzerer V (2015). Determination of the fatty acid composition of the fruits and different organs of lentisk (Pistacia lentiscus L.), J. Essent. Oil-Bear. Plants, 18, 1224-1233.

[27] K. Dimas, S. Hatziantoniou, J.H. Wyche and P. Pantazis (2009). A mastic gum extract induces suppression of growth of human colorectal tumor xenografts in immunodeficient mice, In Vivo, 23, 63-68.

[28] M. Bozorgi, Z. Memariani, M. Mobli, M.H.S. Surmaghi, M.R. Shams-Ardekani and R. Rahimie (2013). Five Pistacia species (P. vera, P. atlantica, P. terebinthus, P. khinjuk and P. lentiscus): A review of their traditional uses, phytochemistry and pharmacology, Sci. World J. 219815.

[29] H. Ben Hassaini, A. Fetati, A.K. Hocine and M. Belkhodja M. (2012). Effect of salt stress on growth and accumulation of proline and soluble sugars on plantlets of Pistacia atlantica Desf. subsp. atlantica used as rootstocks, Biotechnol. Agron. Soc. Environ. 6, 159-165.

[30] F. Kamiab, A. Talaie, A. Javanshah, M. Khezri and A. Khalighi (2012). Effect of long-term salinity on growth, chemical composition and mineral elements of pistachio (Pistacia vera cv. Badamizarand) rootstock seedlings. Ann. Biol. Res. 3, 5545-5551.

[31] Z. Asadollahi and V. Mozaffari (2013). Effects of salinity and manganese on growth and chemical composition of pistachio (Pistacia vera L.) seedlings in perlite medium, J. Sci. Tec. Greenhouse Cult. 3, $13-28$.

[32] S. Ben Hamed and E. Lefi (2015). Dynamics of growth and phytomass allocation in seedlings of Pistacia atlantica Desf. versus Pistacia vera L. under salt stress, IJAAR. 6, 16-27.

[33] G. Cristiano, S. Camposeo, M. Fracchiolla, G.A. Vivaldi, B. De Lucia and E. Cazzato (2016). Salinity differentially affects growth and ecophysiology of two mastic tree (Pistacia lentiscus L.) accessions, Forests 7, 156 (12 pages).

[34] J. Miljuš-Djukić, N. Stanisavljević, S. Radović, Z. Jovanović, A. Mikić and V. Maksimović (2013). Differential response of three contrasting pea (Pisum arvense, P. sativum and P. fulvum) species to salt stress: assessment of variation in antioxidative defence and miRNA expression, Aust. J. Crop Sci. 7, 21452153.

[35] A. Chelli-Chaabouni, A. Ben Mosbah, M. Maalej, K. Gargouri, R. Gargouri-Bouzid and N. Drira (2010). In vitro salinity tolerance of two pistachio rootstocks: Pistacia vera L. and Pistacia atlantica Desf., Environ. Exp. Bot. 69, 302-312.

[36] B. Benmahioul, F. Daguin and M. Kaid-Harche (2009). Effect of salt stress on germination and growth in vitro of the pistachio (Pistacia vera L.), C. R. Biol., 332:752-758.

[37] T. Murashige and F. Skoog (1962). A revised medium for rapid growth and bioassays with tobacco tissue cultures. Physiol. Plant., 15, 473-497.

[38] E. Tilkat, C. Isikalan and A. Onay (2005). In vitro propagation of khinjuk pistachio (Pistacia khinjuk Stocks) through seedling apical shoot tip culture, Propag. Ornam. Plants 5, 124-128.

[39] B. Mohantyand and B.L. Ong (2003). Contrasting effects of submergence in light and dark on pyruvate decarboxylase activity in roots of rice lines differing in submergence tolerance, Ann. Bot. 91, 291-300.

[40] R.K. Sairam, K.V. Rao and G.C. Srivastava (2002). Differential response of wheat genotypes to long term salinity stress in relation to oxidative stress, antioxidant activity and osmolyte concentration, Plant Sci. 163, 1037-1046.

[41] D.I. Arnon (1949). Copper enzymes in isolated chloroplasts polyphanoloxidase in Beta vulgaris, Plant Physiol. 24,1-15.

[42] H.K. Lichtenthaler and A.R. Wellburn (1983). Determinations of total carotenoids and chlorophylls $a$ and $b$ of leaf extracts in different solvents, Biochem. Soc. Trans., 11, 591-592.

[43] S.L.R Ellison and A. Williams (2012). Eurachem/CITAC guide: Quantifying Uncertainty in Analytical Measurement, Third edition, Teddington, UK, pp-141.

[44] W.A. Matebie, W.C. Zhang, S. Zhang and G.B. Xie (2019). Triterpenoids from Acokanthera schimperi in Ethiopia, Rec. Nat. Prod. 13, 182-188.

[45] K. H. Le, T.C. Nguyen, T.A. Nguyen, N.D.P. Nguyen, T.H.T. Do, L.T.T. Nguyen, V.S. Dang, T.D. Tran, N.M. Phan, T.D. Bui, D.T. Mai and T.P. Nguyen (2021). Cytotoxic activity and phytochemical constituents of Macrosolen bidoupensis Tangane \& V.S. Dang, Rec. Nat. Prod. 15, 71-75.

[46] V.S. Dandin and H.N. Murthy (2012). Enhanced in vitro multiplication of Nothapodytes nimmoniana graham using semisolid and liquid cultures and estimation of camptothecin in the regenerated plants, Acta Physiol. Plant, 34, 1381-1386.

[47] J.G. Patil, M.L. Ahire, K.M. Nitnaware, S. Panda, V.P. Bhatt, P.B.K. Kishor and T.D. Nikame (2013). In vitro propagation and production of cardiotonic glycosides in shoot cultures of Digitalis purpurea L. by elicitation and precursor feeding, Appl. Microbiol. Biotechnol. 97, 2379-2393.

[48] S. Munish, A. Ashok, G. Rajinder and M. Sharada (2015). Enhanced bacoside production in shoot cultures of Bacopa monnieri under the influence of abiotic elicitors, Nat. Prod. Res. 29, 745-749. 
[49] M. Bayraktar, E. Naziri, I.H. Akgun, F. Karabey, E. Ilhan, B. Akyol, E. Bedir and A. Gurel (2016). Elicitor induced stevioside production, in vitro shoot growth, and biomass accumulation in micropropagated Stevia rebaudiana, Plant Cell, Tissue Organ Cult., 127, 289-300.

[50] D. Krstić-Milošević, T. Janković, B. Uzelac, D. Vinterhalter and B. Vinterhalter (2017). Effect of elicitors on xanthone accumulation and biomass production in hairy root cultures of Gentiana dinarica. Plant Cell, Tiss. Organ. Cult. 130, 631-640

[51] S.R. Krishnan Saranya, E.A. Siril (2018). Elicitor mediated adventitious root culture for the large-scale production of anthraquinones from Oldenlandia umbellata, L., Ind. Crops Prod. 114, 173-179.

[52] T. Biswas (2020). Elicitor induced increased rosmarinic acid content of in vitro root cultures of Ocimum basilicum L. (Sweet Basil), Plant Sci. Tod. 7, 157-63.

[53] J. Zhao, W.H. Zhu and Q. Hu (2000). Enhanced ajmalicine production in Catharanthus roseus cell cultures by combined elicitor treatment: from shake-flask to 20-1 airlift bioreactor, Biotechnol. Lett. 22, 509-514.

[54] L. Ferguson, P.A. Poss, S.R. Grattan, C.M. Grieve, W. C. Want, T.J. Donovan and C.T. Chao (2002). Pistachio rootstocks influence scion growth and ion relations under salinity and boron stress, J. Am. Soc. Hortic. Sci. 127, 194-199.

[55] A. Ranjbar, P. Van Damme, R. Samson and R. Lemeur (2002). Leaf water status and photosynthetic gas exchange of Pistacia khinjuk and P. mutica exposed to osmotic drought stress, Acta Hortic. 591, 423-428.

[56] M.Y. Ashraf and A.S. Bhatti (2000). Effect of salinity on growth and chlorophyll content in rice, Pak. J. Sci. Ind. Res., 43, 130-131.

[57] H. Hokmabadi, K. Arzani and P.F. Grierson (2005). Growth, chemical composition and carbon isotope discrimination of pistachio (Pistacia vera L.) rootstocks seedlings in response to salinity, Aust. J. Agric. Res. 56, 135-144.

[58] M. Adish, M. Fekri and H. Hokmabadi. (2010). Response of Badami-Zarand pistachio rootstock to salinity stress. IJNRS, 1, 1-111.

[59] S. L. Yan, C.Y. Huang, S.T. Wu and M.C. Yin (2010). Oleanolic acid and ursolic acid induce apoptosis in four human liver cancer cell lines, Toxicol In Vitro, 24, 842-848.

[60] R.J. Thoppil and A. Bishayee (2011). Terpenoids as potential chemopreventive and therapeutic agents in liver cancer. World J. Hepatol. 3, 228-249.

[61] M.H. Shyu, T.C. Kao and G.C. Yen (2010). Oleanolic acid and ursolic acid induce apoptosis in HuH7 human hepatocellular carcinoma cells through a mitochondrial-dependent pathway and downregulation of XIAP, J. Agric. Food Chem. 58, 6110-6118.

[62] Z. Tian, G. Lin, R.X. Zheng, F. Huang, M.S. Yang and P.G. Xiao (2006). Anti-hepatoma activity and mechanism of ursolic acid and its derivatives isolated from Aralia decaisneana, World J. Gastroenterol. 12, 874-879.

[63] C. Giaginis and S. Theocharis (2011). Current evidence on the anticancer potential of chios mastic gum. Nutr. Cancer, 63, 1174-1184.

[64] M.L. He, A. Li, C.S. Xu, S.L. Wang, M.J. Zhang, H. Gu, Y-Q Yang and H.H. Tao (2007). Mechanisms of anti-prostate cancer by gum mastic: NF-kappaB signal as target, Acta Pharmacol. Sin. 28, 446-452.

[65] H. Sakagami, K. Kishino, M. Kobayashi, K. Hashimoto, S. Iida, A. Shimetani,Y. Nakamura, K. Takahashi, T. Ikarashi, H. Fukamachi, K. Satoh, H. Nakashima, T. Shimizu, K. Takeda, S. Watanabe and W. Nakamura (2009). Selective antibacterial and apoptosis-modulating activities of mastic. In Vivo, 23, 215-223.

$$
\underset{\substack{\text { publications } \\ \text { (C) 2021 ACG Publications }}}{\text { C }}
$$

